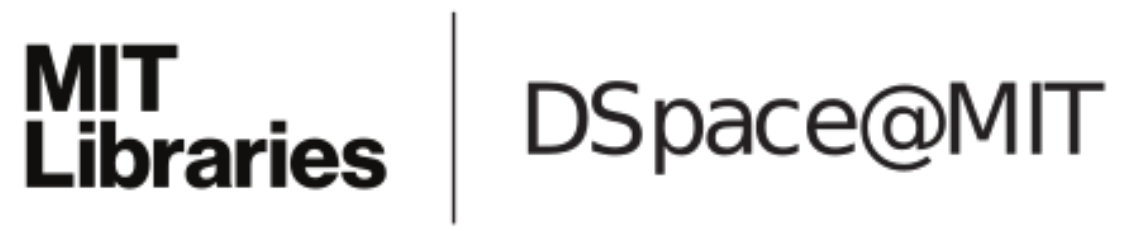

\author{
MIT Open Access Articles
}

A Theory for Buoyancy and Velocity Scales in Deep Moist Convection

The MIT Faculty has made this article openly available. Please share how this access benefits you. Your story matters.

Citation: Parodi, Antonio, and Kerry Emanuel. "A Theory for Buoyancy and Velocity Scales in Deep Moist Convection." Journal of the Atmospheric Sciences 66.11 (2009): 3449-3463. (C 2009 American Meteorological Society

As Published: http://dx.doi.org/10.1175/2009jas3103.1

Publisher: American Meteorological Society

Persistent URL: http://hdl.handle.net/1721.1/55913

Version: Final published version: final published article, as it appeared in a journal, conference proceedings, or other formally published context

Terms of Use: Article is made available in accordance with the publisher's policy and may be subject to US copyright law. Please refer to the publisher's site for terms of use. 


\title{
A Theory for Buoyancy and Velocity Scales in Deep Moist Convection
}

\author{
ANTONIO PARODI \\ CIMA Research Foundation, Savona, Italy \\ KERRY EMANUEL \\ Program in Atmospheres, Oceans, and Climate, Massachusetts Institute of Technology, \\ Cambridge, Massachusetts
}

(Manuscript received 10 February 2009, in final form 12 May 2009)

\begin{abstract}
Buoyancy and velocity scales for dry convection in statistical equilibrium were derived in the early twentieth century by Prandtl, but the scaling of convective velocity and buoyancy, as well as the fractional area coverage of convective clouds, is still unresolved for moist convection.

In this paper, high-resolution simulations of an atmosphere in radiative-convective equilibrium are performed using the Weather Research and Forecasting (WRF) model, a three-dimensional, nonhydrostatic, convection-resolving, limited-area model. The velocity and buoyancy scales for moist convection in statistical equilibrium are characterized by prescribing different constant cooling rates to the system.

It is shown that the spatiotemporal properties of deep moist convection and buoyancy and velocity scales at equilibrium depend on the terminal velocity of raindrops and a hypothesis is developed to explain this behavior. This hypothesis is evaluated and discussed in the context of the numerical results provided by the WRF model. The influence of domain size on radiative-convective equilibrium statistics is also assessed. The dependence of finescale spatiotemporal properties of convective structures on numerical and physical details is investigated.
\end{abstract}

\section{Introduction}

A useful starting point in the study of the tropical climate is the paradigm of moist convection in radiativeconvective equilibrium. In the absence of large-scale circulations, the tropical atmosphere would assume a state of radiative-moist convective equilibrium in which the divergence of the net vertical radiative flux (shortwave and longwave) would be compensated by the convergence of the vertical flux of enthalpy in convective clouds, except for a thin boundary layer near the surface, in which ordinary dry turbulence would carry the flux.

This state is highly idealized and, in general, there is considerable evidence that it is not stable to large-scale perturbations; however, this does not reduce its utility as an equilibrium state.

In this work we show that the spatiotemporal properties of deep moist convection and buoyancy and ve-

Corresponding author address: Antonio Parodi, CIMA Research Foundation, Via Magliotto 2, 17100, Savona, Italy.

E-mail: antonio.parodi@cimafoundation.org locity scales at equilibrium depend on the terminal velocity of raindrops and we develop a hypothesis to explain this. This hypothesis is explored and tested further in section 4.

Although there is presently little understanding of precipitating radiative-convective equilibrium, there have been a number of numerical simulations approximating this state in doubly periodic domains and capped by a stable layer representing the stratosphere. The earliest long-term simulations of moist radiative-convective equilibrium were based on two-dimensional (2D) experiments. Asai and Nakasuji $(1977,1982)$ studied moist convection in a quasi-steady state using a model with simplified microphysics. Among others, Held et al. (1993) studied radiative-convective equilibrium with explicit 2D moist convection, whereas Randall et al. (1994) analyzed radiative-convective equilibrium dynamics with a 2D model that used an interactive radiation scheme.

Although such studies have proven insightful, the need for a three-dimensional (3D) modeling approach to study radiative-convective interactions has become clear, especially to correctly model the interaction between cloud circulations. Islam et al. (1993) and Robe and 
Emanuel (1996) performed 3D simulations of radiativeconvective equilibrium using a cloud-permitting model with imposed radiative cooling and simple microphysical schemes. Tompkins and Craig $(1998,1999)$ ran a 3D cloud-permitting model to a radiative-convective equilibrium state and studied the time scales of adjustment and its sensitivity to changes of sea surface temperature. Robe and Emanuel (2001) showed that vertical wind shear strongly influences the spatial organization of the convection: in its absence, the convection is disorganized but not completely random, whereas a background wind with vertical shear organizes convection in squall lines or arc-shaped structures. Pauluis and Held (2002a,b) addressed the entropy budget of an atmosphere in radiative-convective equilibrium and showed that most of the entropy production is by mixing of moist and dry air and by frictional dissipation associated with falling precipitation.

Although much research has been devoted to the study of moist convection in radiative-convective equilibrium, its spatiotemporal properties are not yet fully understood.

Although Prandtl $(1910,1925)$ derived buoyancy and velocity scales for dry convection in statistical equilibrium, nonetheless in the case of moist convection the scaling of convective velocity and buoyancy scales, as well as the topic of the fractional area coverage of convective clouds, remains unresolved even though there have been several studies of this topic (Rennó and Ingersoll 1996; Craig 1996; Emanuel and Bister 1996; Robe and Emanuel 1996; Klein 1997; Xu and Randall 1998; Shutts and Gray 1999; Robe and Emanuel 2001; Wu 2002; Grabowski 2003).

The formulation of a scaling theory for deep moist convection aims to identify the external parameters that determine the spatiotemporal evolution and other main statistical properties of convection. This topic is relevant and timely with respect to current research efforts (Robe and Emanuel 2001; Arakawa 2004; Pauluis and Held 2002a,b) and there are several scientific reasons for carrying out further research on it.

The absence of such theory impedes our understanding of the feedbacks of changes in large-scale forcing on convective ensembles and the development and testing of comprehensive representations of convection in large-scale models (Arakawa 2004) and thus results in poor modeling of the vertical transport of water and chemical tracers by cumulus convection. A better knowledge of this topic could help in understanding and modeling the phase transition of random convective states to aggregated convection (Bretherton et al. 2005; Nolan et al. 2007) and could provide a deeper insight into the interaction between moist convection and boundary layer convection. Along the same lines, the prediction of the distributions of tracers like water vapor would benefit from a comprehensive formulation of buoyancy and velocity scales, which would also improve the determination of the mass fluxes and mass detrainments associated with each cloud type as well as the organization of cumulus updrafts and downdrafts. The lack of a correct scaling for velocity and buoyancy in moist convection limits our understanding of cloud dynamics and water vapor control by deep convection and affects the extent to which global circulation models (GCMs) can be used as reliable tools to study climate dynamics. Finally, cloud microphysical processes depend strongly on updraft and downdraft velocities, but at present there is no satisfying way of specifying these in convective parameterizations. Therefore, addressing these issues requires the understanding of convective velocity and buoyancy scales in moist convection and a better understanding of the spatiotemporal evolution of the fractional areal coverage of convective clouds.

In this paper, the development of a scaling theory for moist convection in statistical equilibrium is undertaken. High-resolution simulations of an atmosphere in radiative-convective equilibrium are performed using the Weather Research and Forecasting (WRF) model, a 3D cloud-permitting model, and we characterize the velocity and buoyancy scales of moist convection in statistical equilibrium under a variety of different forcings and microphysical specifications. The influence of domain size on radiative-convective equilibrium statistics is assessed and the dependence of finescale spatiotemporal properties of convective structures on numerical and physical details is investigated.

In section 2, the underlying assumptions of the work are presented, together with the design of the corresponding numerical experiments performed with the WRF model. The results of the numerical experiments are described in section 3. Section 4 provides an interpretation of these results through the formulation of a moist scaling theory. A summary is presented in section 5 .

\section{Experimental design}

Robe and Emanuel (1996) quantified moist convective scaling using three-dimensional cloud ensemble simulations. They characterized the sensitivity of an atmosphere in radiative-convective equilibrium to imposed tropospheric radiative cooling rates. They found that the increase of cloud areal coverage accounts for all the increase of the cloud mass flux required for balancing an increase of the radiative cooling rate. At equilibrium, the 
mean updraft velocity in the clouds turned out to be nearly independent of the magnitude of the radiative forcing. Starting from these findings, a different approach to the problem of moist convective scaling is attempted.

The underlying hypothesis of this work is that the spatiotemporal properties of deep moist convection and buoyancy and velocity scales at equilibrium depend on the terminal velocity of raindrops, $V_{T}$. Some evidence supports the choice of the terminal velocity of raindrops as a key parameter in the dynamics of moist convection.

The basic idea here is that if the updraft speed systematically exceeds the terminal velocity of precipitation particles, condensed water will be lofted and accumulate somewhere above the level of peak updraft speed. This would reduce the updraft buoyancy and lead to weaker updrafts. The dependence of buoyancy and velocity scales on the terminal velocity of raindrops is addressed in this work by performing high-resolution numerical simulations of deep moist convection in statistical equilibrium over a horizontally uniform water surface. In this way, the convective dynamics can be resolved explicitly, albeit crudely, and we can bring to bear a detailed representation of cloud microphysics processes.

We employ version 2.2 of the Advanced Research Weather Research and Forecasting model (ARW-WRF), which is a fully compressible, nonhydrostatic, scalar variable-conserving, cloud-resolving model (CRM). Created in 2000 by the National Center for Atmospheric Research (NCAR) and developed continuously since, the WRF model is used for operational forecasting and research purposes. For a comprehensive description of this model, the reader is referred to Skamarock et al. (2005).

As usual, the statistical equilibrium state is represented by a doubly periodic domain capped by a stable layer that represents the stratosphere. The model is run on domains of different sizes $(L=50,100,200$, and $400 \mathrm{~km}$ ) in order to assess the effect of domain size on spatiotemporal properties of moist convection. A uniform horizontal spatial resolution of $2 \mathrm{~km}$ is adopted here, while the vertical grid spacing stretches gradually from $100 \mathrm{~m}$ near the bottom boundary to $500 \mathrm{~m}$ near the top one.

The microphysics is parameterized according to the scheme of Kessler (1969), which was taken from the Collaborative Model for Multiscale Atmospheric Simulation (COMMAS) (Wicker 1990; Wicker and Wilhelmson 1995) and is a simple warm cloud scheme that includes water vapor, cloud water, and rain. The microphysical processes include the production, fall, and evaporation of rain; the accretion and autoconversion of cloud water; and the production of cloud water from condensation. Ice processes are not considered. The physical and numerical formulations of these microphysical processes will be slightly modified, according to the underlying hypothesis of the work, to allow us to prescribe values of the $V_{T}$ that are constant and independent of the precipitation size distribution. The investigated range of $V_{T}$ will be quite large in order to check the sensitivity of convective dynamics to different values of this key microphysical variable. The lower boundary is a passive ocean with constant temperature $T_{S}=$ $300.15 \mathrm{~K}$. The subgrid-scale turbulence is represented using a level-1.5 3D moist turbulence parameterization (Mellor and Yamada 1974), which is especially suitable for high-resolution numerical modeling of deep moist convection.

As in previous works (e.g., Robe and Emanuel 1996; Grabowski 2003), a constant cooling rate $Q_{\text {rad }}$ is applied over the depth of the troposphere $(0<z<15 \mathrm{~km})$, while above it a sponge layer relaxes the scalar state variables back to observed stratospheric profiles. Such an approach allows one to separate the direct influence of cloud microphysics on convective dynamics from the indirect influence of clouds on radiative cooling. As we will show, cloud microphysics exerts a significant influence on the mean temperature and moisture profiles even though interactions of radiation with cloud and water vapor are neglected. In this work, moist convection scaling has been studied for three different cooling rates $Q_{\text {rad }}\left(-2,-4\right.$, and $\left.-6 \mathrm{~K}_{\text {day }}{ }^{-1}\right)$. The use of different cooling rates allows us to assess the dependence of convective properties on such rates. We chose to use rates on the high side of observed rates to accelerate the approach to equilibrium. To partially account for the effect of a mean surface wind, which is absent in our model setting, and also to accelerate the approach to moist statistical equilibrium, a minimum wind speed of $10 \mathrm{~m} \mathrm{~s}^{-1}$ is added to the actual wind speed in the computation of surface moisture and heat fluxes.

The initial atmosphere is horizontally homogeneous, with a vertical temperature profile similar to Jordan's (1958) sounding for the hurricane season in the West Indies. The atmosphere is made unstable by the aforementioned constant radiative cooling from the surface to the tropopause coupled with surface enthalpy fluxes. The convection is triggered with spatially random temperature perturbations in the lower atmosphere $(0<z<$ $2500 \mathrm{~m})$. The perturbations range from -0.5 to $0.5 \mathrm{~K}$ but do not produce domain-averaged heating.

Because the main results of the work pertain to a domain size $L$ of $200 \mathrm{~km}$, the following procedure has been adopted to speed up the computations. For each cooling rate and precipitation terminal velocity, the simulations are run over a domain of size of $100 \mathrm{~km}$ until radiative-convective equilibrium has been achieved (after about 20-25 days). Then the mean temperature and water vapor profiles at equilibrium are used to 
restart the simulation over a domain of size $200 \mathrm{~km}$ for a period of 10 days.

The discussion of the results of these numerical experiments is focused on two main aspects:

- analysis of the dependence of the space-time properties of convective structures on the applied range of the precipitation terminal velocities, and

- interpretation of the numerical experiments for different cooling rates (e.g., $-2,-4$, and $-6 \mathrm{~K} \mathrm{day}^{-1}$ ) through the formulation of a moist scaling theory.

\section{Analysis of the dependence of the properties of convection on the terminal velocity of raindrops}

For each prescribed cooling rate $Q_{\text {rad }}$, an ensemble of simulations with different precipitation terminal velocities $\left(2 \leq V_{T} \leq 50 \mathrm{~m} \mathrm{~s}^{-1}\right)$ is performed; here we present and compare the results. The expected value of raindrop terminal velocity is around $5 \mathrm{~m} \mathrm{~s}^{-1}$, but the explored range of $V_{T}$ has been extended considerably in order to quantify the sensitivity of various metrics of convection to different values of this key microphysical variable.

\section{a. Effect of the computational domain size}

We first explore the effect of computational domain size on the statistical properties of moist convection in statistical equilibrium. In particular, we show here, for the case of $Q_{\text {rad }}=-4 \mathrm{~K} \mathrm{day}^{-1}$ and $V_{T}=5 \mathrm{~m} \mathrm{~s}^{-1}$, how some simple statistical properties of the flow field, such as the vertical velocity value at $z=5000 \mathrm{~m}, w_{p}$ (the upper quantile of vertical velocity corresponding to a value of the cumulative distribution function $F=0.9999$ ), converge in a statistical sense when the domain size increases from $L=25 \mathrm{~km}$ to $L=400 \mathrm{~km}$.

Figure 1 shows how the value of $w_{p}$ depends on the computational domain size $\left(V_{T}=5 \mathrm{~m} \mathrm{~s}^{-1}\right.$ and $Q_{\mathrm{rad}}=$ $\left.-4 \mathrm{~K} \mathrm{day}^{-1}\right)$. This finding is in agreement with Bretherton et al. (2005) and suggests a strong underestimation of velocities in the cores of the convective cells when $L$ is too small. Similar results are obtained in this study for other values of $V_{T}$. In this work, as a compromise between computational expense and statistical reliability of the results, a reference domain size $L$ of $200 \mathrm{~km}$ is chosen; at this domain size, the convective velocity scales derived from the numerical findings and their corresponding evaluation against the proposed theory will not be overly dependent on the domain size.

\section{b. Radiative-convective equilibrium statistics}

This section discusses how the raindrop terminal velocity $V_{T}$ influences radiative-convective equilibrium

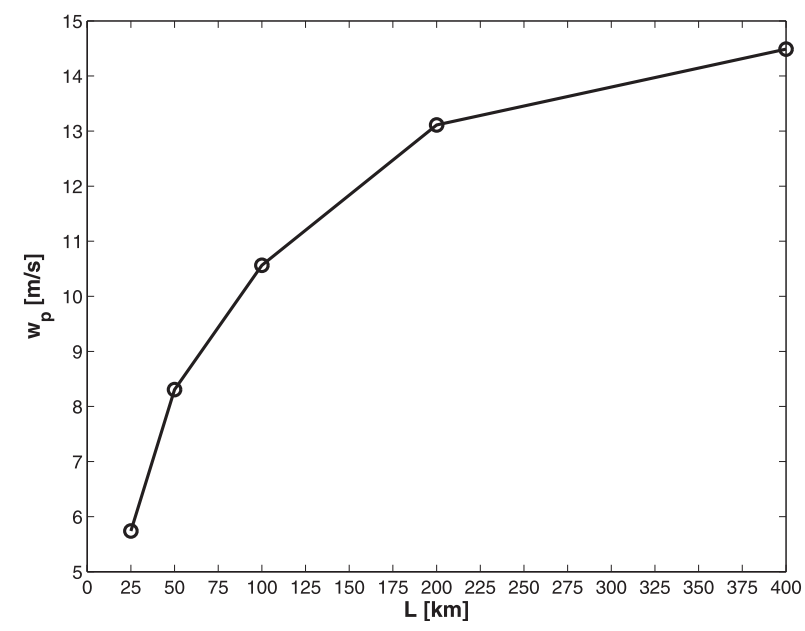

FIG. 1. Dependence of $w_{p}$ on the computational domain size $\left(V_{T}=5 \mathrm{~m} \mathrm{~s}^{-1}\right.$ and $\left.Q_{\mathrm{rad}}=-4 \mathrm{~K} \mathrm{day}^{-1}\right)$.

statistics when a constant cooling rate is prescribed. It is important to bear in mind that we are not here interested in the influence of $V_{T}$ on the dynamics of a single cloud system but rather in its influence on some general statistics of radiative-convective equilibrium. In general, the results discussed in this section are in good agreement with those provided by Grabowski (2003).

The evolution of the mean temperature at any level is determined by the balance among radiative cooling, latent heating, convective transport, and parameterized subgrid-scale (e.g., turbulence) fluxes. The quasiequilibrium temperature profile is established once the sum of all terms on right-hand side of temperature tendency equation becomes zero.

For prescribed cooling rates $Q_{\mathrm{rad}}=-2,-4$, and $-6 \mathrm{~K} \mathrm{day}^{-1}$, Fig. 2a shows the difference between the domain mean temperature and that of a reference profile $\left(V_{T}=5 \mathrm{~m} \mathrm{~s}^{-1}\right)$, averaged over a period of 5 days in radiative-convective equilibrium, for two different values of $V_{T}=2$ and $15 \mathrm{~m} \mathrm{~s}^{-1}$.

Temperature profiles are warmer when a smaller raindrop terminal velocity $V_{T}$ is used. The peak of the negative temperature difference between low- and high$V_{T}$ simulations is located in the middle troposphere: here the convective term and the subgrid-scale turbulent term dominate the enthalpy transport toward the upper troposphere. These two terms produce a stronger (negative) contribution to the temperature tendency profile when high values of the raindrop terminal velocity $V_{T}$ are considered.

However, within the boundary layer, the high- $V_{T}$ simulations are about a degree warmer than the runs characterized by low- $V_{T}$ values: this is owing to the 

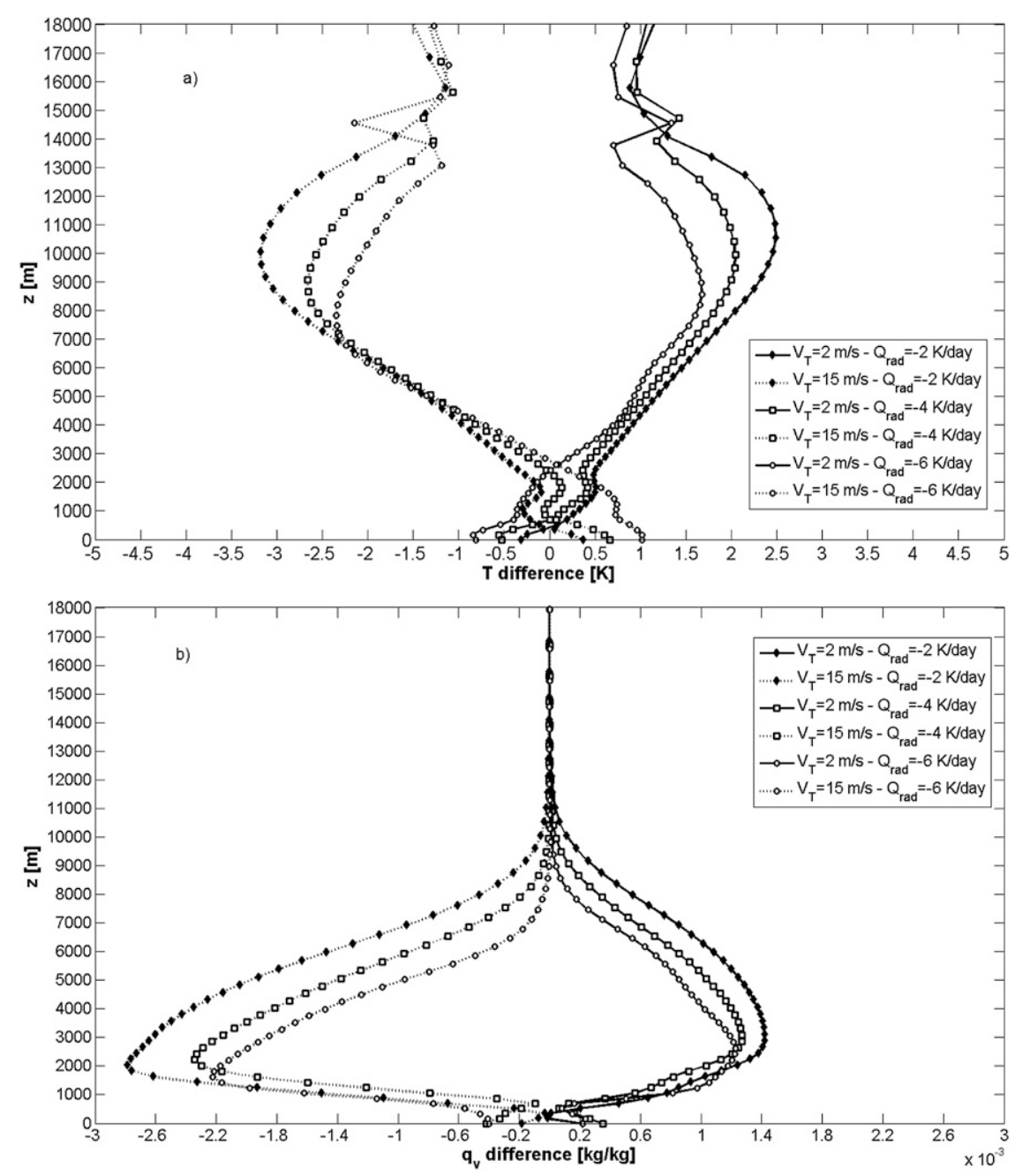

FIG. 2. (a) Difference from a reference equilibrium temperature and (b) $q_{v}$ profile $\left(V_{T}=\right.$ $\left.5 \mathrm{~m} \mathrm{~s}^{-1}\right)$ in the case of lower and higher values of $V_{T}\left(2\right.$ and $\left.15 \mathrm{~m} \mathrm{~s}^{-1}\right)$ for different cooling rates $\left(Q_{\mathrm{rad}}=-2,-4\right.$, and $\left.-6 \mathrm{~K}_{\text {day }^{-1}}\right)$.

lower evaporation rate in the subcloud layer because of the shorter residence time of raindrops in the atmosphere when $V_{T}$ is higher.

Similar conclusions about the effect of raindrop terminal velocity on the equilibrium statistics can be drawn when the profiles of moisture ( $q_{v}$ field) are analyzed. The simulations characterized by high values of $V_{T}$ generate a drier atmosphere, especially in the middle troposphere around $2000-4000 \mathrm{~m}$. There the difference between water vapor content for high- and low- $V_{T}$ runs is around $1-2 \mathrm{~g} \mathrm{~kg}^{-1}$ (Fig. 2b). The drying may be owing to the lower residence time of precipitation in the troposphere, leading to smaller humidity.

In this framework Pauluis and Held (2002a) considered energy and entropy budgets averaged over the whole domain in simulations of radiative-convective equilibrium using a cloud-permitting model, while they did not consider the buoyancy of individual clouds as we do here. However, it is worth mentioning that in our simulation we have found that the thermal part of the buoyancy flux and the precipitation-induced dissipation decrease with raindrop terminal velocity (not shown here).

\section{c. Moist convective scaling: Rainfall results}

Because the main goal of this study is to address some basic scaling issues of moist radiative-convective equilibrium, a simple algorithm for estimating the rainfall intensity of convective cells from each spatial frame field has been developed on the basis of the following procedure (von Hardenberg et al. 2003): a local maximum 

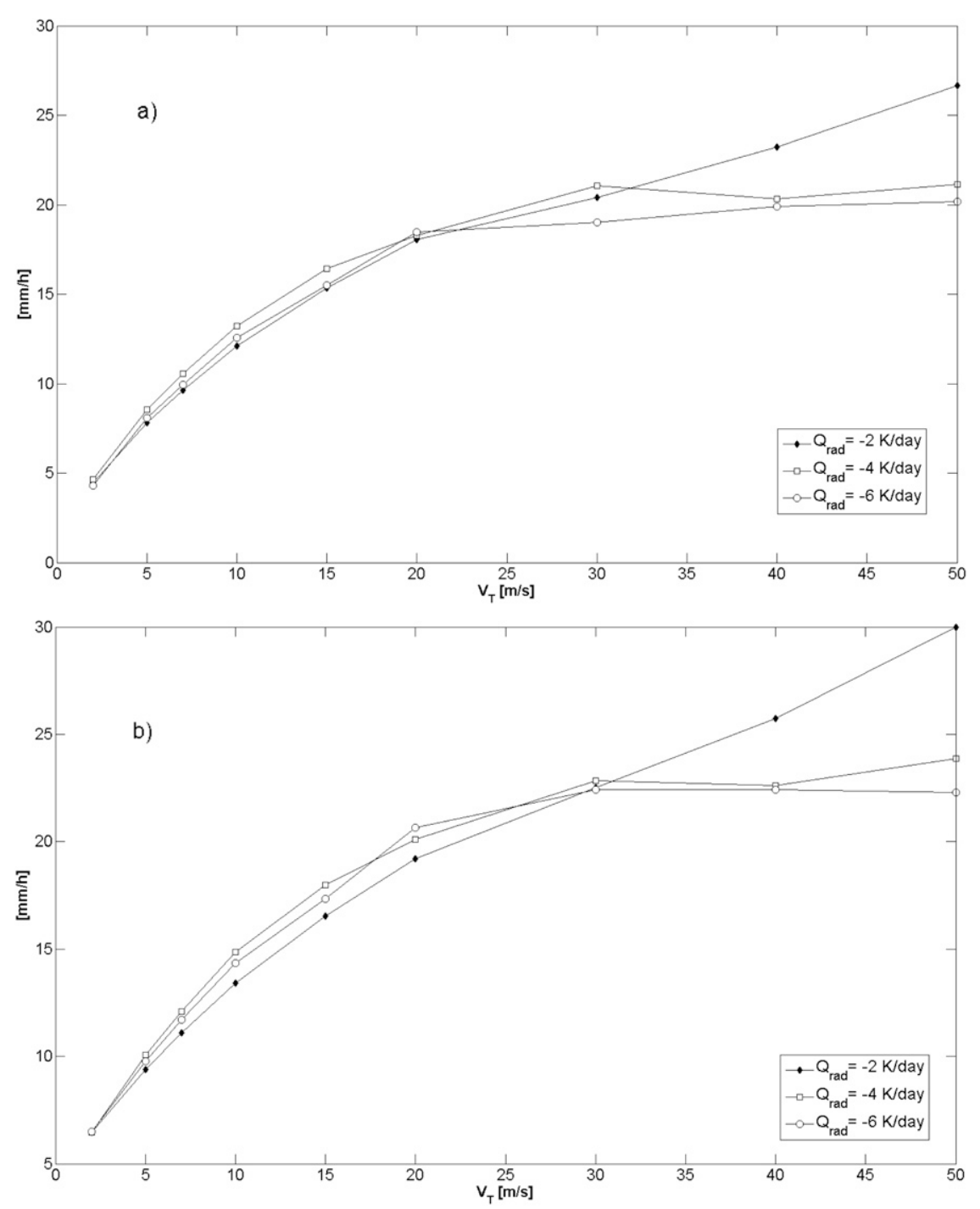

FIG. 3. Scaling of mean rainfall intensity vs raindrop terminal velocity $V_{T}$ in the convective cell core; threshold for rain cell detection equal to (a) 10 and (b) $30 \mathrm{~mm} \mathrm{~h}^{-1}$.

in the rainfall intensity field $R$ is defined as a pixel value that is larger than any of its 20 nearest neighbors. Each maximum represents a cell. Around each cell center, progressively lower contour levels are traced and the horizontal extent of each rain cell is that identifying the connected region around each maximum that has an intensity larger than a chosen level. In this work, we retain only those maxima in $R$ that exceed one of two thresholds: 10 and $30 \mathrm{~mm} \mathrm{~h}^{-1}$. The horizontal extent of each rain cell is then determined by identifying the connected region around the maximum that has $R$ larger than $0.5 \mathrm{~mm} \mathrm{~h}^{-1}$. For each cell, the spatial average of rainfall intensity over this connected region is computed.
The mean of the rainfall intensities is computed during a period of 5 days in radiative-convective equilibrium: the scaling of these simple statistical properties against the raindrop terminal velocity $V_{T}$ is analyzed for different cooling rates $Q_{\text {rad }}$ (Fig. 3). The mean rainfall intensity exhibits an interesting dependence, for each prescribed cooling rate, on the value of the terminal velocity $V_{T}$. When $V_{T}$ increases from a value of $2 \mathrm{~m} \mathrm{~s}^{-1}$ to about $20 \mathrm{~m} \mathrm{~s}^{-1}$, these cell statistics increase nearly linearly at first but then asymptote to constant values at high $V_{T}$.

The increase of the rain intensity as $V_{T}$ increases is confirmed, from a qualitative point of view, by comparing two instantaneous frames of the rainfall intensity 
field for $V_{T}=2$ and $10 \mathrm{~m} \mathrm{~s}^{-1}\left(Q_{\mathrm{rad}}=-4 \mathrm{~K} \mathrm{day}^{-1}\right)$. When the terminal velocity is larger, the convective cells are stronger and smaller in size, and more random and isolated (Fig. 4), whereas in the case of the low- $V_{T}$ experiments, the rainfall field exhibits a regular pattern, reminiscent of a Rayleigh-Benard convection organization. This important result is confirmed when the mean of the cells area is plotted as a function of the raindrop terminal velocity. When $V_{T}$ increases, the cells on average tend to shrink (Fig. 5a) and their number tends to decrease (Fig. 5b).

The important role of $V_{T}$ in the rainfall statistics is also evident in other water-related quantities, such as the vertically integrated condensed water content (Fig. 5c).

\section{d. Moist convective scaling: Updraft velocity results}

To address the topic of the scaling results of the updraft vertical velocity, we first consider the dependence on the raindrop terminal velocity $V_{T}$ of the vertical velocity value at $z=5000 \mathrm{~m}, w_{p}$. This updraft velocity scale shows, for each cooling rate, an increase with $V_{T}$ in the range $2-10 \mathrm{~m} \mathrm{~s}^{-1}$ and a gradual asymptoting to a constant value at large values of $V_{T}$ (Fig. 6). Similar findings are obtained for this quantile at elevations $z=$ 2000 and $z=8000 \mathrm{~m}$ (not shown here).

These results support the underlying premise of this work that identifies the raindrop terminal velocity as a key physical parameter that governs the intensity of deep moist convection in statistical equilibrium.

We extend these diagnostics to provide a more comprehensive view of the updraft velocity field. We first define an objective criterion to identify the computational pixels corresponding to a true convective updraft. To achieve this, we calculated the cumulative distribution function of the vertical velocity field, at $z=5000 \mathrm{~m}$, for a period of 5 days in radiativeconvective equilibrium, both for low and high $V_{T}$ values, in the case of $Q_{\mathrm{rad}}=-4 \mathrm{~K} \mathrm{day}^{-1}$. The total probability of $w>2 \mathrm{~m} \mathrm{~s}^{-1}$ is on the order of $1 \%$ while the bulk of the distribution lies at very low values $\left(<1 \mathrm{~m} \mathrm{~s}^{-1}\right)$ (Fig. 7). Similar conclusions hold for the other cooling rates; we regard a value of $w$ of $2 \mathrm{~m} \mathrm{~s}^{-1}$ as a threshold for the identification of the updraft pixels, in good agreement with other definitions present in the literature.

The scaling of the mean value of the updraft velocity, thus defined ( $w_{\text {updraft }}$ ) and averaged in the range $1000<z<5000 \mathrm{~m}$ over a period of 5 days in radiativeconvective equilibrium, is now addressed. For each cooling rate, the mean updraft velocity scales nearly linearly with the raindrop terminal velocity in the range between
2 and $20 \mathrm{~m} \mathrm{~s}^{-1}$, whereas for higher values it begins to asymptote to a constant value dependent on the cooling rate (Fig. 8).

\section{Interpretation of the numerical experiments through the formulation of a moist convective scaling theory}

We here provide a physical interpretation of the governing role of the precipitation fall velocity on deep moist convection properties. Our interpretation rests on three key assumptions, each of which is evaluated using the WRF model outputs.

\section{a. Key assumptions of the moist scaling theory}

The buoyancy of an air parcel lifted to some level can be broken into two parts: a part owing to temperature excess and a part owing to liquid water loading:

$$
B \approx g \frac{\alpha^{\prime}}{\bar{\alpha}}-g l^{\prime} \approx g \frac{T_{v}^{\prime}}{\overline{T_{v}}}-g l^{\prime},
$$

where $\alpha$ is specific volume, $l^{\prime}$ is the liquid water concentration, $T_{v}$ is the virtual temperature, $g$ is the acceleration of gravity, and the primes denote deviations (at constant pressure) from the base state, represented by an overbar.

Expressing $\alpha$ as a function of pressure and saturation moist entropy $s^{*}$ and using one of the Maxwell's relations (Emanuel 1994), the above expression can be written as

$$
B \approx \Gamma s^{*^{\prime}}-g l^{\prime},
$$

where $\Gamma$ is the moist adiabatic lapse rate. Here we have neglected the contribution of water vapor to the density fluctuations.

We suppose that the fluctuations of saturation entropy in the cloud are directly related to fluctuations of actual entropy in the boundary layer, allowing us to rewrite Eq. (2) as

$$
B \approx \Gamma s^{\prime}-g l^{\prime} .
$$

Integrating Eq. (3) over the cloud layer and assuming that all of the buoyancy can be converted to kinetic energy results in the following expression for the kinetic energy of the vertical velocity component: 

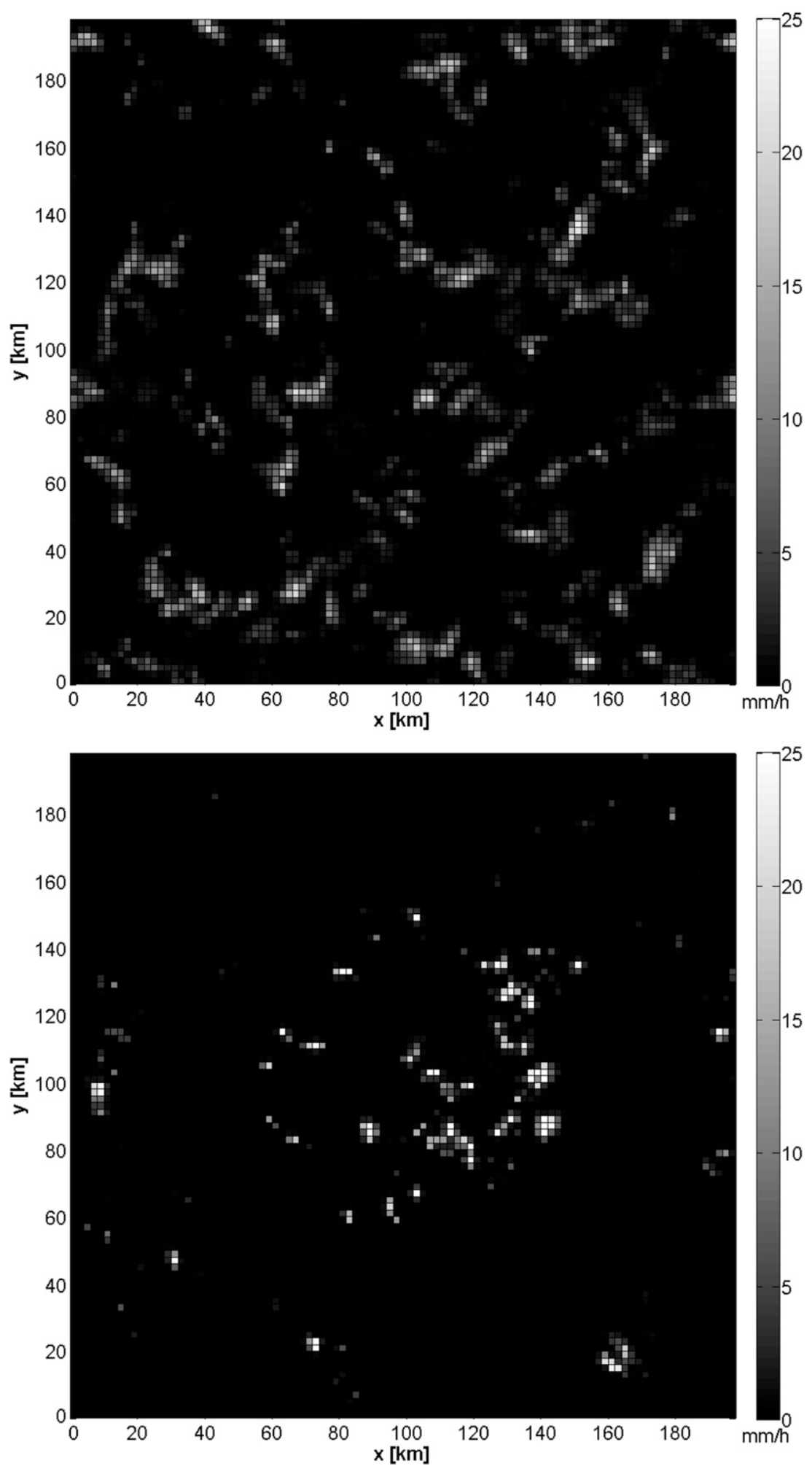

FIG. 4. Instantaneous frame of the rainfall intensity field for $V_{T}=$ (top) 2 and (bottom) $10 \mathrm{~m} \mathrm{~s}^{-1} ; Q_{\mathrm{rad}}=-4 \mathrm{~K} \mathrm{day}^{-1}$. 

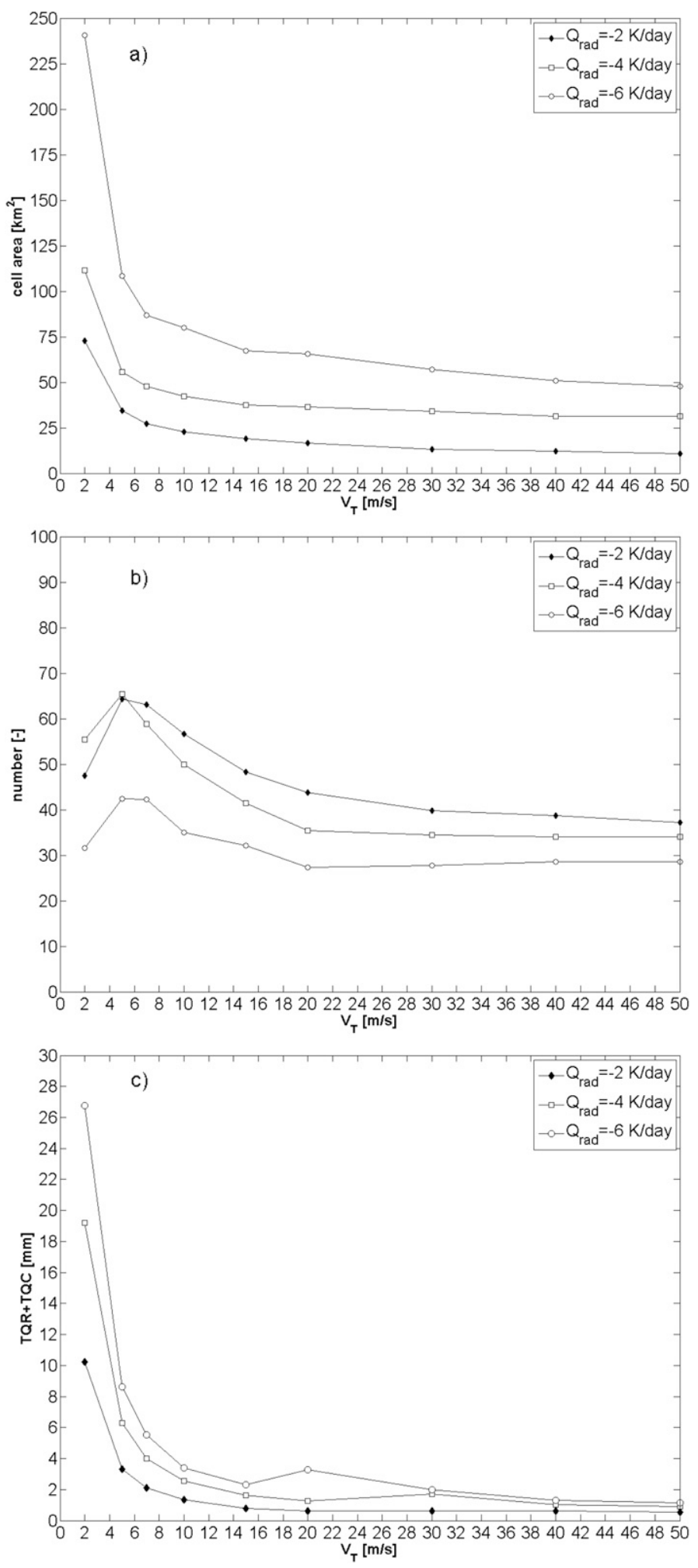

FIG. 5. (a),(b) Scaling of the mean value of the cell (a) area and (b) number vs the raindrop terminal velocity $V_{T}$ (threshold for rain cell detection equal to $10 \mathrm{~mm} \mathrm{~h}^{-1}$ ). (c) Scaling of the mean value of the columnar content (cloud water + rainwater) vs the raindrop terminal velocity $V_{T}$. 


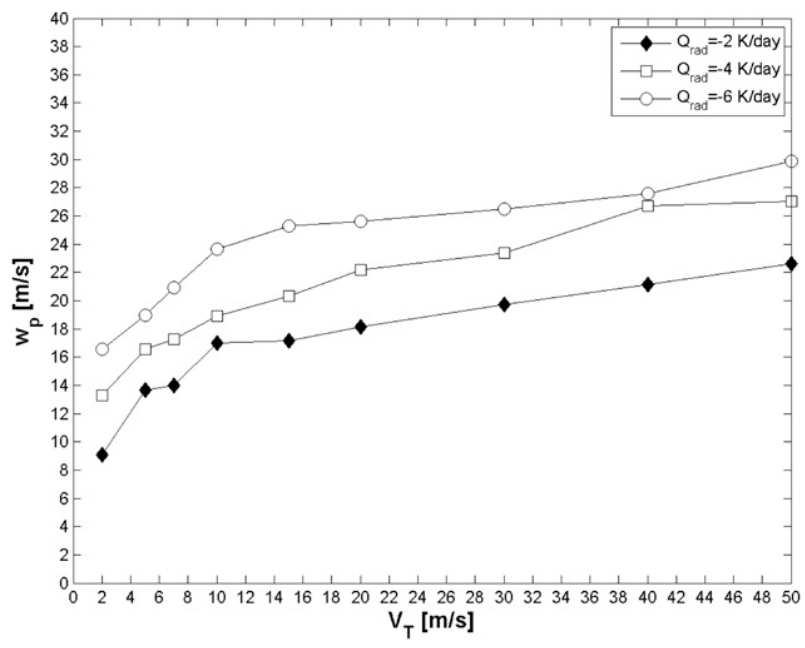

FIG. 6. Scaling of the updraft velocity, corresponding to the quantile $F=0.9999$, vs the raindrop terminal velocity $V_{T}$.

$$
\frac{1}{2} w^{2} \approx\left(\Delta T s^{\prime}-g H_{q} l^{\prime}\right)=a s^{\prime}-b l^{\prime}
$$

where $\Delta T$ is the temperature difference across the depth of the convective layer, $H_{q}$ is a scale height for liquid water concentration, $s^{\prime}$ is a boundary layer value, and $l^{\prime}$ is a vertically averaged value. The tuning coefficients $a$ and $b$ will be estimated in the following section through the evaluation of this expression against the results provided by the numerical experiments, with different raindrop terminal velocities $V_{T}$ and different cooling rates $Q_{\text {rad. }}$ Equation (4) accounts for water loading but does not account for turbulent mixing, which dilutes both the buoyancy and the momentum of updrafts. Bear in mind that we are seeking scaling relations, not exact equations.

To estimate $l^{\prime}$ in Eq. (4), a local balance between the fall of rainwater and the upward transport of water vapor is postulated so that water substance does not accumulate in any layer:

$$
w q^{*} \approx V_{T} l^{\prime}=c V_{T} l^{\prime}+d,
$$

where $q^{*}$ is a characteristic difference between the specific humidity in and outside the cloud. In Eq. (4), the tuning coefficients $c$ and $d$ will be estimated in the following section through the evaluation of this expression against the results provided by the numerical experiments, with different raindrop terminal velocities $V_{T}$ and different cooling rates $Q_{\text {rad }}$. The coefficient $d$ has been adopted as a residual term to compensate for the simplified nature of this water budget equation.

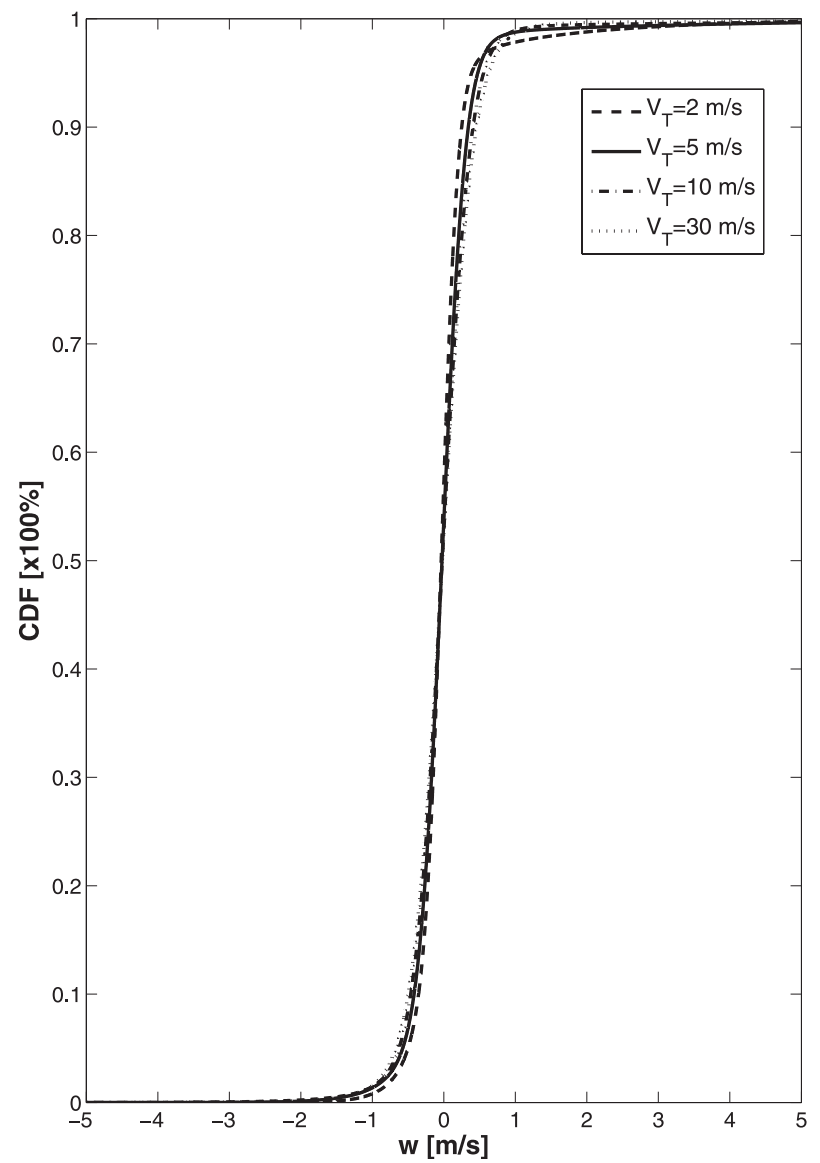

FIG. 7. Cumulative distribution function of the vertical velocity field at $z=5000 \mathrm{~m}\left(Q_{\mathrm{rad}}=-4 \mathrm{~K} \mathrm{day}^{-1}\right)$.

Equation (5) is combined with Eq. (4) to obtain the following quadratic moist scaling equation:

$$
c V_{T} w^{2}+b q^{*} w-a c s^{\prime} V_{T}-b d=0 .
$$

A preliminary interpretation of this quadratic moist scaling equation is here provided. In the limit of large $V_{T}$, all liquid falls out, and $w$ is given by $s^{\prime}$, independent of $l^{\prime}$ and thus $V_{T}$ : this is confirmed by the asymptotic behavior visible in Fig. 6 and, especially, Fig. 8. In the limit of small $V_{T}$ (no precipitation), $l$ should approach the adiabatic water content and, according to Eq. (5), this should be achieved by $w$ becoming similar to $V_{T}$ : this is partially supported by Figs. 6 and 8 , where there is some evidence of a linear relationship for $V_{T}$ in the range 2-7 $\mathrm{m} \mathrm{s}^{-1}$.

The rest of this paper is devoted to evaluating quantitatively this moist scaling theory against high-resolution numerical results. The evaluation of the proposed moist scaling theory follows three independent steps, described below. 


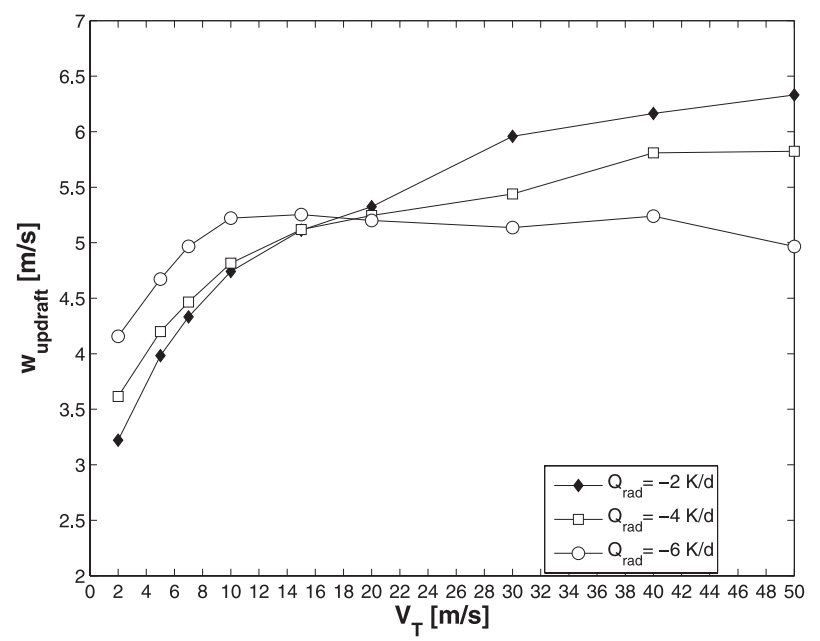

FIG. 8. Scaling of mean value of updraft velocity over the whole domain vs the raindrop terminal velocity $V_{T}$.

\section{b. Evaluation of the key equations of the scaling theory against the numerical experiments}

The first step focuses on the definition and computation of the main scales appearing in the formulation of the theory: $q^{*}, s^{\prime}$, and $l^{\prime}$.

The scale $q^{*}$ has been evaluated as a characteristic difference between in-cloud and outside cloud values at about the same altitude $(z=3000 \mathrm{~m})$. The scale $s^{\prime}$, used for the assessment of the Eq. (4), is defined as the mean value of the moist entropy standard deviation over the layer $0-500 \mathrm{~m}$ : it is representative of the intensity of moist entropy-related processes occurring locally in the boundary layer. The variables $T_{v}^{\prime} / \overline{T_{v}}$ and $l^{\prime}$, used for computation of the buoyancy $B$ in Eq. (1), are evaluated over a period of 5 days in statistical equilibrium for each $V_{T}$ and $Q_{\mathrm{rad}}$, according to the following procedure:

(i) At each level $z, T_{v}^{\prime}$ is defined as the average difference between virtual temperature at cloudy points $T_{c}\left(w>2 \mathrm{~m} \mathrm{~s}^{-1}\right.$ and cloud water mass fraction $\left.q_{c} \geq 10^{-5} \mathrm{~kg} \mathrm{~kg}^{-1}\right)$ and the virtual temperature at noncloudy points $T_{\mathrm{nc}}$ (rainwater sedimentation flux $>2 \mathrm{~mm} \mathrm{~h}^{-1}$ and cloud water mass fraction $\left.q_{c}<10^{-5} \mathrm{~kg} \mathrm{~kg}^{-1}\right)$. This average is computed only over those points where such difference is positive.

(ii) At each level $z, l_{q}^{\prime}$ is the average value of the total condensed water $q_{r}+q_{c}$ over the points where the aforementioned difference $T_{c}-T_{\mathrm{nc}}$ is positive.

(iii) At each level $z, \overline{T_{v}}$ is the spatial average value of virtual temperature $T_{v}$.

Along these lines, the corresponding profiles of buoyancy $B$ for the different $V_{T}$ values and for cooling rate

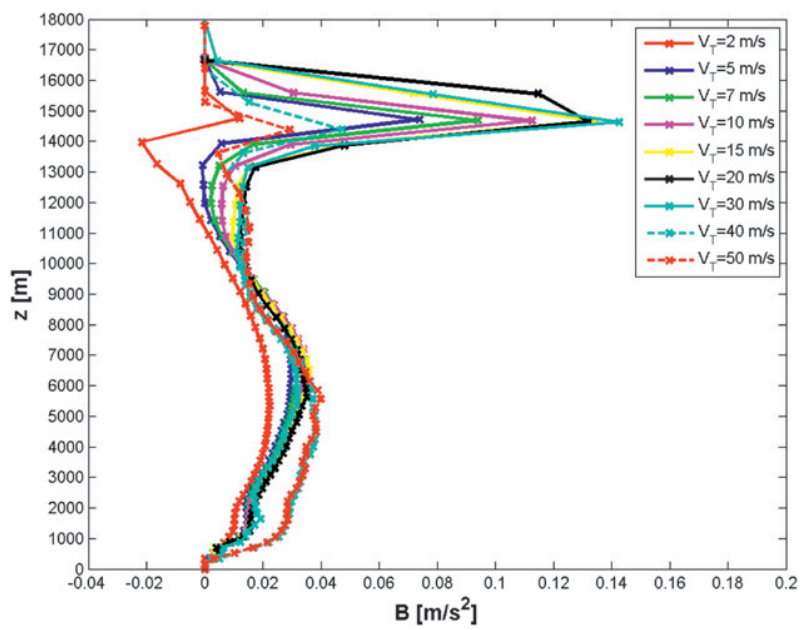

FIG. 9. Profiles of buoyancy $B$ for the cooling rate $Q_{\mathrm{rad}}=-4 \mathrm{~K} \mathrm{day}^{-1}$.

$Q_{\text {rad }}=-4 \mathrm{~K} \mathrm{day}^{-1}$ are shown in Fig. 9; similar findings are valid for cooling rates of $Q_{\mathrm{rad}}=-2$ and $-6 \mathrm{~K} \mathrm{day}^{-1}$. The values of the different scales are presented in Tables 1-3: the scale for the liquid water concentration $l^{\prime}$ is defined as the mean value of $l_{q}^{\prime}$ over the layer $0-8000 \mathrm{~m}$. The second step in the evaluation of the moist scaling theory requires the assessment of the key Eqs. (1), (3), (4), and (5) against the results provided by the numerical experiments.

Equation (1), when integrated over $z$, provides the kinetic energy of the vertical velocity component,

$$
w^{2} \approx \int_{0}^{H}\left[g \frac{T_{v}^{\prime}}{\overline{T_{v}}}-g l^{\prime}\right] d z,
$$

where a value $H=8000 \mathrm{~m}$ is adopted. This equation has been verified, both for the mean and upper quantile updraft cases, according to the scales discussed above: the goal is to determine to what extent (1) holds. The results suggest a good agreement between the updraft velocity values provided by (1) and those obtained by

TABLE 1. Scales for the definition of the moist scaling theory (case $Q_{\text {rad }}=-2 \mathrm{~K} \mathrm{day}^{-1}$ ).

\begin{tabular}{cccc}
\hline$V_{T}\left(\mathrm{~m} \mathrm{~s}^{-1}\right)$ & $q^{*}\left(\mathrm{~kg} \mathrm{~kg}^{-1}\right)$ & $s^{\prime}\left(\mathrm{J} \mathrm{kg}^{-1} \mathrm{~K}^{-1}\right)$ & $l^{\prime}\left(\mathrm{kg} \mathrm{kg}^{-1}\right)$ \\
\hline 2 & $6.61 \times 10^{-3}$ & 21.34 & $1.20 \times 10^{-3}$ \\
5 & $7.88 \times 10^{-3}$ & 23.05 & $1.00 \times 10^{-3}$ \\
7 & $8.59 \times 10^{-3}$ & 22.93 & $9.00 \times 10^{-4}$ \\
10 & $9.49 \times 10^{-3}$ & 23.61 & $9.00 \times 10^{-4}$ \\
15 & $1.06 \times 10^{-2}$ & 25.10 & $8.00 \times 10^{-4}$ \\
20 & $1.13 \times 10^{-2}$ & 26.32 & $7.00 \times 10^{-4}$ \\
30 & $1.13 \times 10^{-2}$ & 31.88 & $5.00 \times 10^{-4}$ \\
40 & $1.13 \times 10^{-2}$ & 33.00 & $4.00 \times 10^{-4}$ \\
50 & $1.13 \times 10^{-2}$ & 34.21 & $4.00 \times 10^{-4}$ \\
\hline
\end{tabular}


TABLE 2. Scales for the definition of the moist scaling theory (case $\left.Q_{\text {rad }}=-4 \mathrm{~K} \mathrm{day}^{-1}\right)$.

\begin{tabular}{cccc}
\hline \hline$V_{T}\left(\mathrm{~m} \mathrm{~s}^{-1}\right)$ & $q^{*}\left(\mathrm{~kg} \mathrm{~kg}^{-1}\right)$ & $s^{\prime}\left(\mathrm{J} \mathrm{kg}^{-1} \mathrm{~K}^{-1}\right)$ & $l^{\prime}\left(\mathrm{kg} \mathrm{kg}^{-1}\right)$ \\
\hline 2 & $6.11 \times 10^{-3}$ & 21.95 & $1.20 \times 10^{-3}$ \\
5 & $7.10 \times 10^{-3}$ & 24.99 & $1.00 \times 10^{-3}$ \\
7 & $7.70 \times 10^{-3}$ & 25.76 & $9.00 \times 10^{-4}$ \\
10 & $8.31 \times 10^{-3}$ & 26.22 & $8.00 \times 10^{-4}$ \\
15 & $9.10 \times 10^{-3}$ & 26.27 & $7.00 \times 10^{-4}$ \\
20 & $9.59 \times 10^{-3}$ & 26.49 & $6.00 \times 10^{-4}$ \\
30 & $1.01 \times 10^{-2}$ & 24.56 & $4.00 \times 10^{-4}$ \\
40 & $1.05 \times 10^{-2}$ & 35.72 & $4.00 \times 10^{-4}$ \\
50 & $1.06 \times 10^{-2}$ & 34.76 & $3.00 \times 10^{-4}$ \\
\hline
\end{tabular}

the numerical experiments for the different cooling rates: in the first case (Fig. 10a) the regression coefficient $R^{2}$ is equal to 0.88 , whereas in the second (Fig. 10b) it is lower, about 0.52 .

Another hypothesis to be tested is whether the boundary layer entropy predicts cloud temperature: if this hypothesis is confirmed by the numerical experiments, this could validate (3) and (4). To test it, the vertical profiles of $T^{\prime} / \bar{T}$ have been estimated, for each cooling rate $Q_{\text {rad }}$ and each terminal velocity $V_{T}$, over the same points defined by steps (i)-(iii) of the aforementioned procedure. Then the average of these profiles over the layer $0-8000 \mathrm{~m}$ is plotted against $s^{\prime}$ for each cooling rate $Q_{\text {rad. }}$. The results shown in Fig. 11 are quite satisfactory and confirm the reliability of (3): the regression coefficient $R^{2}$ is about 0.72 . Consequently it is possible to estimate the values of the coefficients $a$ and $b$, according to (4). The results of the multiple regression analysis are reported in Table 4 for the mean and peak updraft case.

The simplified water budget Eq. (5) has also been evaluated against the numerical experiments. The left and right sides of this equation have been computed to assess whether a linear relationship holds (Figs. 12a,b). Once again, the result is positive as confirmed by the values of the determination coefficient $R^{2}$ (around 0.8)

TABLE 3. Scales for the definition of the moist scaling theory (case $Q_{\text {rad }}=-6 \mathrm{~K}$ day $\left.^{-1}\right)$.

\begin{tabular}{cccc}
\hline \hline$V_{T}\left(\mathrm{~m} \mathrm{~s}^{-1}\right)$ & $q^{*}\left(\mathrm{~kg} \mathrm{~kg}^{-1}\right)$ & $s^{\prime}\left(\mathrm{J} \mathrm{kg}^{-1} \mathrm{~K}^{-1}\right)$ & $l^{\prime}\left(\mathrm{kg} \mathrm{kg}^{-1}\right)$ \\
\hline 2 & $5.41 \times 10^{-3}$ & 25.60 & $1.40 \times 10^{-3}$ \\
5 & $6.51 \times 10^{-3}$ & 32.17 & $9.00 \times 10^{-4}$ \\
7 & $6.91 \times 10^{-3}$ & 34.52 & $8.00 \times 10^{-4}$ \\
10 & $7.30 \times 10^{-3}$ & 38.79 & $6.00 \times 10^{-4}$ \\
15 & $7.99 \times 10^{-3}$ & 41.15 & $5.00 \times 10^{-4}$ \\
20 & $8.10 \times 10^{-3}$ & 40.01 & $6.00 \times 10^{-4}$ \\
30 & $8.51 \times 10^{-3}$ & 40.02 & $4.00 \times 10^{-4}$ \\
40 & $8.51 \times 10^{-3}$ & 40.39 & $2.00 \times 10^{-4}$ \\
50 & $8.70 \times 10^{-3}$ & 41.25 & $3.00 \times 10^{-4}$ \\
\hline
\end{tabular}
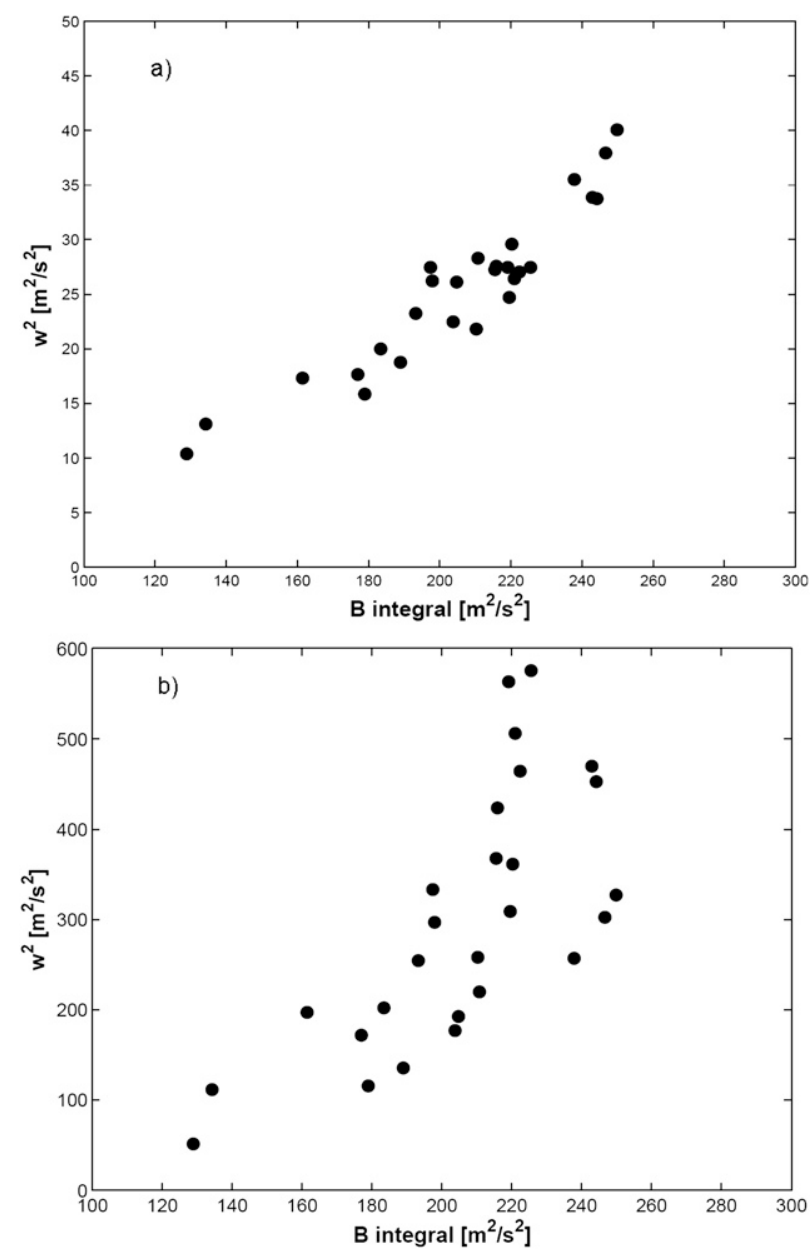

FIG. 10. Evaluation of Eq. (1) for the (a) mean updraft and (b) upper quantile updraft cases $\left(Q_{\mathrm{rad}}=-2,-4\right.$, and $\left.-6 \mathrm{~K} \mathrm{day}^{-1}\right)$. The coefficient of determination is $R^{2}=0.88$ for the mean updraft case and $R^{2}=0.52$ for upper quantile updraft case.

and provided by Table 5: the coefficients $c$ and $d$ are available both for the mean and peak updraft cases.

\section{c. Evaluation of the quadratic moist convective scaling equation}

The quadratic scaling Eq. (6) has been solved for the different cooling rates, where the values of the scales $s^{\prime}$ and $q^{*}$ are provided by Tables $1-3$, and the parameters of the multilinear and linear regressions, $a, b, c$ and $d$, are provided by Tables 4 and 5 . The results are presented in Fig. 13 both for the mean (Fig. 13a) and upper quantile updraft (Fig. 13b) cases. The comparison is quite satisfactory: the mean absolute error (MAE) is about $0.5 \mathrm{~m} \mathrm{~s}^{-1}$ for the mean updraft case and $1.35 \mathrm{~m} \mathrm{~s}^{-1}$ for the upper quantile updraft case, while the bias is negligible in both cases. These simple statistics support 


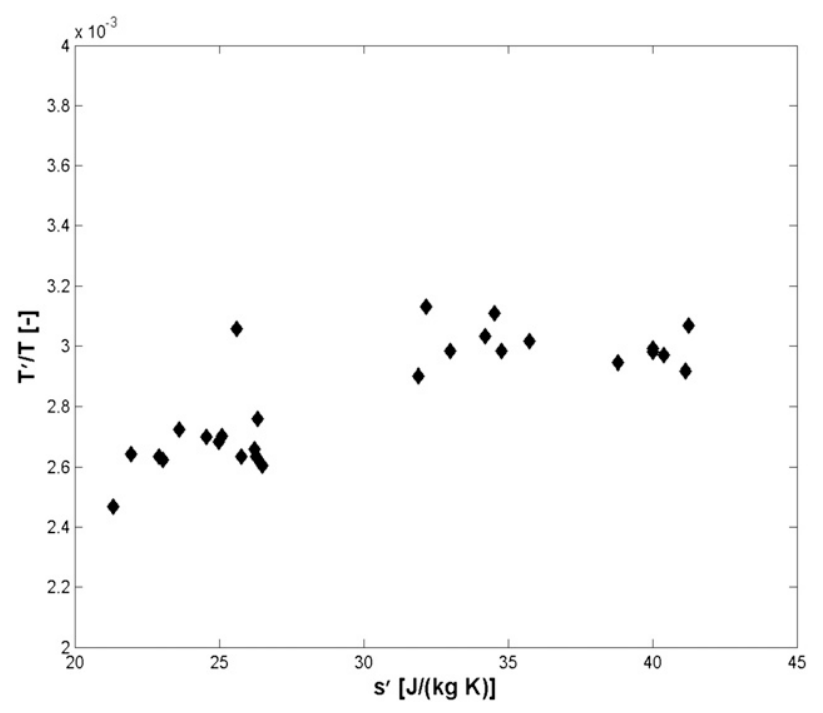

FIG. 11. Cloud temperature $T^{\prime} / \bar{T}$ vs subcloud layer entropy $s^{\prime}$ scale. The coefficient of determination is $R^{2}=0.72$.

the underlying conclusion of this paper that the fall velocity of precipitation is an important physical parameter governing the intensity of deep moist convection in statistical equilibrium. This result should help achieve a deeper understanding of precipitating radiativeconvective equilibrium and improve the understanding of cloud dynamics and water vapor control by deep convection.

Along the same lines, some results shown here suggest that this theory could help in understanding and modeling the phase transition of random convective states to organized tropical cyclone-dominated convection and provide a deeper insight into the interaction between moist convective plumes and boundary layer convection.

\section{Conclusions}

High-resolution simulations of an atmosphere in radiative-convective equilibrium are performed using the WRF model, a three-dimensional, nonhydrostatic, convection-resolving, limited-area model. Prescribing different constant cooling rates to the system, we char-

TABLE 4. Linear regression coefficients for Eq. (4) (mean and upper quantile updraft cases).

\begin{tabular}{lcc}
\hline \multicolumn{1}{c}{ Case } & $a\left(\mathrm{~K}^{-1}\right)$ & $b\left(\mathrm{~m}^{2} \mathrm{~s}^{-2}\right)$ \\
\hline Mean updraft & 0.89 & $3.46 \times 10^{-3}$ \\
Upper quantile updraft & 12.86 & $1.35 \times 10^{-5}$ \\
\hline
\end{tabular}
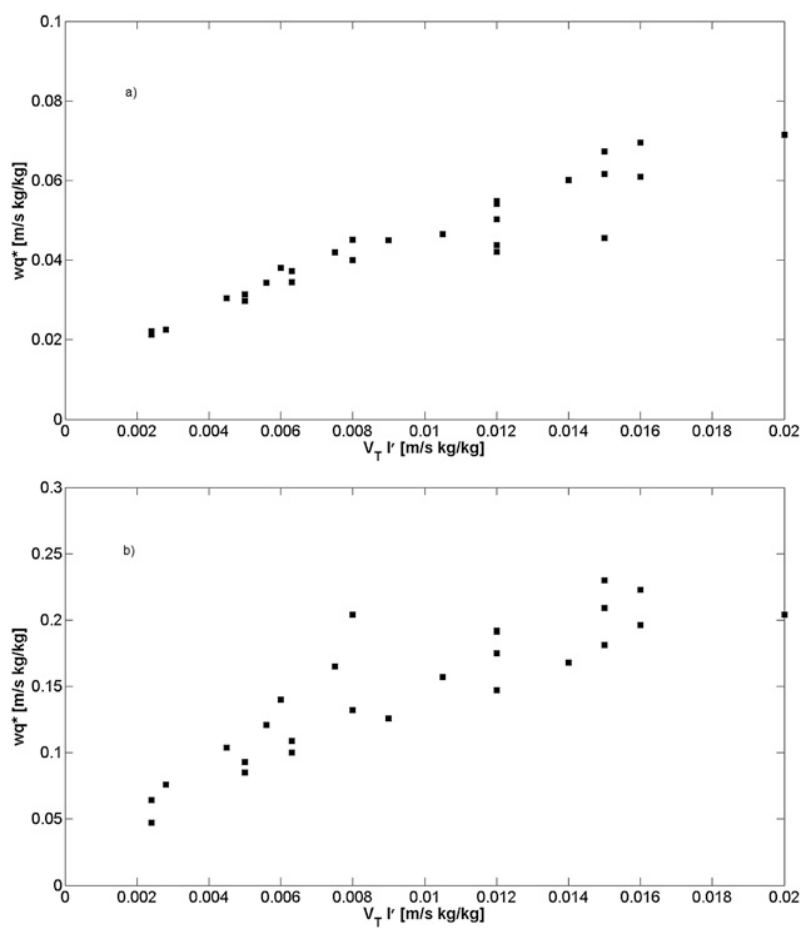

FIG. 12. Evaluation of Eq. (5) (water budget equation) for the (a) mean updraft and (b) peak updraft cases. The coefficient of determination is $R^{2}=0.90$ for the mean updraft case and $R^{2}=0.78$ for the peak one.

acterize the velocity and buoyancy scales for moist convection in statistical equilibrium.

We find that the convective updraft velocity and rainfall intensity scale with the raindrop terminal velocity for sufficiently small values of the terminal velocity, becoming more dependent on thermal buoyancy at large terminal velocity. A new moist scaling theory based on this underlying premise is presented and evaluated against the numerical findings: the results support the basic hypothesis. Further work is currently being undertaken to extend the proposed theory to the timevarying case.

Acknowledgments. The authors are grateful to F. Siccardi, A. Provenzale, L. Ferraris, D. Nolan, and L. Back for enlightening discussions and useful comments. Gratitude is also extended to the reviewers for

TABLE 5. Linear regression coefficients and determination coefficient for Eq. (5) (mean and upper quantile updraft cases).

\begin{tabular}{lccc}
\hline \hline \multicolumn{1}{c}{ Case } & $c$ & $d\left(\mathrm{~kg} \mathrm{~kg}^{-1} \mathrm{~m}^{-1} \mathrm{~s}^{-1}\right)$ & $R^{2}$ \\
\hline Mean updraft & 2.817 & 0.017 & 0.89 \\
Upper quantile updraft & 9.374 & 0.058 & 0.78 \\
\hline
\end{tabular}



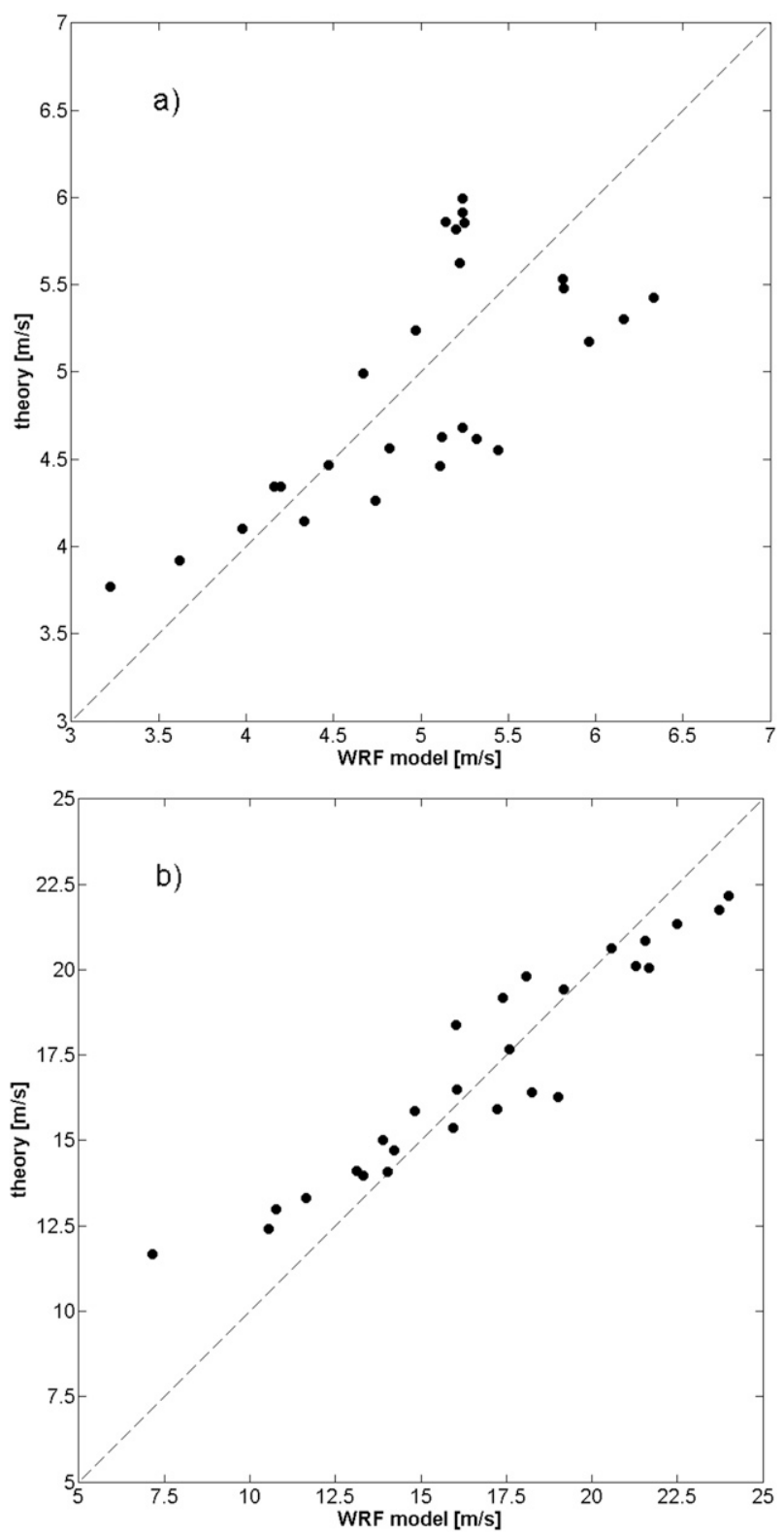

FIG. 13. Comparison between theory and modeling results for the (a) mean updraft velocity and (b) upper updraft velocity cases $\left(Q_{\mathrm{rad}}=-2,-4\right.$, and $-6 \mathrm{~K}$ day $\left.^{-1}\right)$.

the useful comments and to NCAR's computational center for the support in the numerical simulations.

\section{REFERENCES}

Arakawa, A., 2004: The cumulus parameterization problem: Past, present, and future. J. Climate, 17, 2493-2525.

Asai, T., and I. Nakasuji, 1977: On the preferred mode of cumulus convection in a conditionally unstable atmosphere. J. Meteor. Soc. Japan, 55, 151-167.
— and - 1982: A further study of the preferred mode of cumulus convection in a conditionally unstable atmosphere. J. Meteor. Soc. Japan, 60, 425-430.

Bretherton, C., P. Blossey, and M. Khairoutdinov, 2005: An energy-balance analysis of deep convective self-aggregation above uniform SST. J. Atmos. Sci., 62, 4273-4292.

Craig, G. C., 1996: Dimensional analysis of a convecting atmosphere in equilibrium with external forcing. Quart. J. Roy. Meteor. Soc., 122, 1963-1967.

Emanuel, K., 1994: Atmospheric Convection. Oxford University Press, $580 \mathrm{pp}$.

— scales. J. Atmos. Sci., 53, 3276-3285.

Grabowski, W. W., 2003: Impact of cloud microphysics on convective-radiative quasi equilibrium revealed by cloudresolving convection parameterization. J. Climate, 16, $3463-$ 3475.

Held, I. M., R. S. Hemler, and V. Ramaswamy, 1993: Radiativeconvective equilibrium with explicit two-dimensional moist convection. J. Atmos. Sci., 50, 3909-3927.

Islam, S., R. L. Bras, and K. Emanuel, 1993: Predictability of mesoscale rainfall in the tropics. J. Appl. Meteor., 32, 297-310.

Jordan, C. L., 1958: Mean soundings for the West Indies area. J. Meteor., 15, 91-97.

Kessler, E., 1969: On the Distribution and Continuity of Water Substance in Atmospheric Circulation. Meteor. Monogr., No. 32, Amer. Meteor. Soc., 84 pp.

Klein, S. A., 1997: Comments on "Moist convective velocity and buoyancy scales.” J. Atmos. Sci., 54, 2775-2777.

Mellor, G. L., and T. Yamada, 1974: A hierarchy of turbulence closure models for planetary boundary layers. J. Atmos. Sci., 31, 1791-1806.

Nolan, D., E. Rappin, and K. Emanuel, 2007: Tropical cyclogenesis sensitivity to environmental parameters in radiativeconvective equilibrium. Quart. J. Roy. Meteor. Soc., 133, 2085-2107.

Pauluis, O., and I. M. Held, 2002a: Entropy budget of an atmosphere in radiative-convective equilibrium. Part I: Maximum work and frictional dissipation. J. Atmos. Sci., 59, $125-139$.

— , and — 2002b: Entropy budget of an atmosphere in radiative-convective equilibrium. Part II: Latent heat transport and moist processes. J. Atmos. Sci., 59, 140-149.

Prandtl, L., 1910: Eine Beziehung zwischen Wärmeaustausch und Strömungswiderstand der Flüssigkeiten. Phys. Z., 11, 1072-1078.

_ 1925: Bericht über Untersuchungen zur ausgebildeten Turbulenz. Z. Angew. Math. Mech., 5, 136-139.

Randall, D. A., K.-M. Xu, Q. Hu, and S. Krueger, 1994: Radiativeconvective disequilibrium. Atmos. Res., 31, 315-327.

Rennó, N., and P. A. Ingersoll, 1996: Natural convection as a heat engine: A theory for CAPE. J. Atmos. Sci., 53, 572-585.

Robe, F. R., and K. Emanuel, 1996: Moist convective scaling: Some inferences from three-dimensional cloud ensemble simulations. J. Atmos. Sci., 53, 3265-3275.

- , and — 2001: The effect of vertical wind shear on radiative-convective equilibrium states. J. Atmos. Sci., 58, 1427-1445.

Shutts, G. J., and M. E. B. Gray, 1999: Numerical simulations of convective equilibrium under prescribed forcing. Quart. J. Roy. Meteor. Soc., 125, 2767-2787. 
Skamarock, W. C., J. B. Klemp, J. Dudhia, D. O. Gill, D. M. Barker, W. Wang, and J. G. Powers, 2005: A description of the Advanced Research WRF version 2. NCAR Tech. Note NCAR/ TN-468+STR, 88 pp.

Tompkins, A. M., and G. C. Craig, 1998: Radiative-convective equilibrium in a three-dimensional cloud ensemble model. Quart. J. Roy. Meteor. Soc., 124, 2073-2097.

_ face temperature in the absence of large-scale flow. J. Climate, 12, 462-476.

von Hardenberg, J., L. Ferraris, and A. Provenzale, 2003: The shape of convective rain cells. Geophys. Res. Lett., 30, 2280, doi:10.1029/2003GL018539.
Wicker, L. J., 1990: A numerical simulation of a tornado-scale vortex in a three-dimensional cloud model. Ph.D. dissertation, Department of Atmospheric Sciences, University of Illinois, $224 \mathrm{pp}$.

— , and R. Wilhelmson, 1995: Simulation and analysis of tornado development and decay within a three-dimensional supercell thunderstorm. J. Atmos. Sci., 52, 2675-2703.

Wu, W., 2002: Effects of ice microphysics on tropical radiativeconvective oceanic quasi-equilibrium states. J. Atmos. Sci., 59, 1885-1897.

Xu, K.-M., and D. A. Randall, 1998: Influence of large-scale advective cooling and moistening effects on the quasi-equilibrium behavior of explicitly simulated cumulus ensembles. J. Atmos. Sci., 55, 896-909. 